\title{
Control of grain orientation and its impact on carrier mobility in reactively sputtered $\mathrm{Cu}_{2} \mathrm{O}$ thin films
}

Sanggil Han* and Andrew J. Flewitt

Electrical Engineering Division, Cambridge University, 9 JJ Thomson Avenue, CB3 0FA, Cambridge, United Kingdom

*Corresponding author: Sanggil Han

Tel: +44 (0) 1223762412

Email: sh810@cam.ac.uk

Address: Electrical Engineering Division, Cambridge University, 9 JJ Thomson Avenue, CB3 0FA, Cambridge, United Kingdom 


\title{
Control of grain orientation and its impact on carrier mobility in reactively sputtered $\mathrm{Cu}_{2} \mathrm{O}$ thin films
}

Sanggil Han an and Andrew J. Flewitt

Electrical Engineering Division, Cambridge University, 9 JJ Thomson Avenue, CB3

OFA, Cambridge, United Kingdom

\begin{abstract}
Grain orientation can be particularly important in devices such as thin film transistors (TFTs) where grain boundaries present a barrier to lateral carrier transport. This paper demonstrates that thin films of nanocrystalline cuprous oxide $\left(\mathrm{Cu}_{2} \mathrm{O}\right)$ can be grown with control of the grain orientation in the direction of either [111] or [100] perpendicular to the substrate surface using a high target utilization sputtering system. This allows a systematic study of the effect of grain orientation on the carrier mobility in $\mathrm{Cu}_{2} \mathrm{O}$ films. It is shown that the carrier mobility in as-deposited films is similar for both grain orientations while [100]-oriented thin films exhibit a higher carrier mobility for lateral conduction than films with a [111] orientation after annealing, which is discussed from the viewpoint of the Urbach energy, crystallinity and surface morphology. This experimental finding suggests that $\mathrm{Cu}_{2} \mathrm{O}$ thin films with a [100]
\end{abstract}


surface grain orientation are favorable for device applications such as p-type TFTs where a high in-plane carrier mobility is desired.

Keywords: p-type metal oxide, Cuprous oxide, Sputtering, Carrier mobility, Grain orientation

\section{Introduction}

Cuprous oxide $\left(\mathrm{Cu}_{2} \mathrm{O}\right)$ has been proposed as a suitable channel layer for p-type metal oxide thin film transistors (TFTs) since effective hole transport is expected due to its unique orbital configuration. To be specific, energy levels of the $\mathrm{Cu} 3 d$ and $\mathrm{O} 2 p$ orbitals are comparable in $\mathrm{Cu}_{2} \mathrm{O}$, which leads to considerable covalency in the ionic metal-oxygen bonds. This results in not only a large dispersion near the top of the valence band but also a considerable reduction in the localization of holes by $\mathrm{O} 2 p$ orbitals, leading to effective carrier transport [1-3]. However, actual nanocrystalline $\mathrm{Cu}_{2} \mathrm{O}$ thin films have grain boundaries with a high degree of structural disorder (i.e. many trap states), and therefore lateral carrier transport is significantly degraded by grain boundary scattering and carrier trapping at trap states [4]. Our previous report demonstrated that vacuum annealing can be used to improve the low carrier mobility in $\mathrm{Cu}_{2} \mathrm{O}$ films without phase conversion to either $\mathrm{CuO}$ or $\mathrm{Cu}[5]$.

Grain orientation can also affect the carrier mobility in $\mathrm{Cu}_{2} \mathrm{O}$ films where grain boundaries impede carrier transport. Most of the existing literature on control of the $\mathrm{Cu}_{2} \mathrm{O}$ 
grain orientation is based on the electrodeposition method and it was shown that the grain orientation is controlled by its several deposition parameters (e.g. electrolyte $\mathrm{pH}$ and potential applied to the electrode) [6-10]. However, the conductive substrate required for electrodeposition causes difficulty in accurately measuring electrical characteristics of a $\mathrm{Cu}_{2} \mathrm{O}$ film itself, which hinders a systematic investigation into the effect of grain orientation on the carrier mobility. This can be easily solved through control of the grain orientation by vacuum process techniques (e.g. reactive sputtering and chemical vapor deposition) enabling the use of an insulating substrate such as glass.

Films generally tend to grow with the crystalline plane of the lowest surface energy parallel to the substrate surface to minimize the surface energy [11,12]. It was found that an increase in adatom mobility enables the growth of crystalline planes different from that of the lowest surface energy [12-14]. In the case of $\mathrm{Cu}_{2} \mathrm{O}$, the nonpolar (111) plane was demonstrated to have the lowest surface energy $E_{S}\left(0.677 \mathrm{~J} \cdot \mathrm{m}^{-2}\right)$ [15]. Based on the surface energy consideration alone, $\mathrm{Cu}_{2} \mathrm{O}$ films are expected to have the [111] preferred grain orientation. Wang et al. showed that the preferred orientation in sputtered $\mathrm{Cu}_{2} \mathrm{O}$ films can be changed from the [111] direction to the [100] direction (which has a significantly higher surface energy of $1.194 \mathrm{~J} \cdot \mathrm{m}^{-2}$ [15]) by an increase in adatom mobility through adjusting the process pressure [14]. In addition to the process pressure, the ion-to-metal flux ratio $\left(J_{i} / J_{m e}\right)$ incident at the growing film during sputter deposition is known to be a control parameter for the kinetic energy of adatoms (i.e. adatom mobility) [16,17]. For example, an increase in $J_{i} / J_{m e}$ leads to an increase in the number of energetic ions which collides with each metal 
adatom at the growing film surface, which results in an increase in ion-adatom momentum transfer (i.e. higher adatom mobility).

A high target utilization sputtering (HiTUS) system (Plasma Quest Limited) enables a precise control of $J_{i} / J_{m e}$ through simply adjusting the ion current $\left(i_{C}\right)$ which is a sputtering parameter related to an Ar plasma density at the surface of a metal target (see a detailed description and a schematic diagram of HiTUS in Ref [18]). Specifically, in the case of reactive sputtering of $\mathrm{Cu}_{2} \mathrm{O}$, the ion flux $\left(J_{i}\right)$ incident at the growing film mainly consists of the ions generated by the $\mathrm{Ar}$ and $\mathrm{O}_{2}$ plasma near to the grounded substrate holder. An increased $i_{C}$ means an increase in the Ar plasma density at the $\mathrm{Cu}$ target surface, which leads to more $\mathrm{Cu}$ atoms being emitted from the target (i.e. a higher $\mathrm{Cu}$ flux, $J_{C u}$ ). On the other hand, the change in $i_{C}$ has a negligible effect on the Ar plasma density near to the growing film and the $\mathrm{O}_{2}$ plasma remains constant by using the same oxygen flow rate, which allows the assumption of a constant $J_{i}$. Therefore, an increase in $i_{C}$ results in a reduction in $J_{i} / J_{C u}$ (i.e. $i_{C}$ is inversely related to $\left.J_{i} / J_{C u}\right)$.

In this letter, it is demonstrated that $\mathrm{Cu}_{2} \mathrm{O}$ films can be grown with control of the grain orientation in the direction of either [111] or [100] perpendicular to the substrate surface through adjusting $i_{C}$ of the HiTUS system. This allows an investigation to determine which one of the two grain orientations is more favorable in terms of the in-plane carrier mobility. Furthermore, the impact of grain orientation on the carrier mobility in both as-deposited and annealed films of $\mathrm{Cu}_{2} \mathrm{O}$ is discussed based on the Urbach energy, crystallinity and surface morphology. 


\section{Experimental Details}

$\mathrm{Cu}_{2} \mathrm{O}$ thin films were deposited by the HiTUS system from a metallic $\mathrm{Cu}$ target with 4inch diameter and $99.999 \%$ purity (Kurt J. Lesker Company) in an $\mathrm{Ar} / \mathrm{O}_{2}$ gas mixture (99.9995\% purity; BOC Gases Ltd). The base pressure in the chamber was $6.0 \times 10^{-4} \mathrm{~Pa}$, and Ar gas was provided to set a process pressure of $1.5 \times 10^{-1} \mathrm{~Pa}$. The reactive sputtering was performed at a constant DC bias voltage (a sputtering parameter related to ion energy, $E_{i}$ ) of $690 \mathrm{~V}$ and an oxygen flow rate of $16 \mathrm{sccm}$ without intentional substrate heating. $i_{C}$ was varied from $1.38 \mathrm{~A}$ to $1.52 \mathrm{~A}$ in order to investigate the $J_{i} / J_{C u}$ dependence on the $\mathrm{Cu}_{2} \mathrm{O}$ grain orientation. Surface profilometry (Veeco Dektak 200SI) was used to measure film thickness. The film thickness increased from 500 to $550 \mathrm{~nm}$ with an increase in $i_{C}$ from 1.38 to $1.52 \mathrm{~A}$. The films were annealed at various temperatures $\left(500,600\right.$ and $\left.700{ }^{\circ} \mathrm{C}\right)$ for $10 \mathrm{~min}$ in vacuum $\left(9.5 \times 10^{-2} \mathrm{~Pa}\right)$ in an Aixtron Cambridge Nanoinstruments Black Magic 2 system. An infrared (IR) radiation pyrometer (Infratherm IGA8 plus) was used for monitoring the annealing temperature. The temperature ramp rate was $5 \mathrm{~K} \mathrm{~s}^{-1}$ and all the annealed films were unloaded at a chamber temperature of $50{ }^{\circ} \mathrm{C}$. Four $\mathrm{Au}$ electrodes were formed at the corners of the $\mathrm{Cu}_{2} \mathrm{O}$ films deposited on $8 \mathrm{~mm} \times 8 \mathrm{~mm}$ glass (Corning 7059 ) substrates using a thermal evaporator (Edwards E306A) and a shadow mask in order to measure Hall mobility $\left(\mu_{\text {Hall }}\right)$ using the van der Pauw method.

In order to check grain orientation of $\mathrm{Cu}_{2} \mathrm{O}$ thin films, X-ray diffraction (XRD) patterns were obtained using a Bruker D8 Discover X-ray diffractometer with the following measurement set-up: $\mathrm{Cu} \mathrm{K} \mathrm{K}_{\alpha 1} \mathrm{X}$-ray source with a wavelength of $0.154 \mathrm{~nm}, \mathrm{X}$-ray generator 
power $(40 \mathrm{kV}$ and $40 \mathrm{~mA})$, monochromator slit size $(0.2 \mathrm{~mm})$ and scan speed $(1.5 \mathrm{sec} / \mathrm{step})$. $\mu_{\text {Hall }}$ was obtained based on the conventional measuring standard in the van der Pauw configuration using an MMR Technologies Hall Effect Measurement System (K2500-7) at room temperature. Specifically, thermoelectric and misalignment offsets are corrected by reversing the direction of current flow and magnetic field, and then $\mu_{\text {Hall }}$ is determined by averaging the corrected Hall voltages along the two diagonals of the sample. Furthermore, a Hall scattering factor $(1 \leq r \leq 2)$ reflecting intrinsic scattering mechanisms in single crystals or grains was approximated to be $r=1$ in the $\mu_{\text {Hall }}$ calculations since the $\mu_{\text {Hall }}$ values are used for the purpose of comparing an apparent mobility including the grain boundary effect, not a true in-grain carrier mobility, between the [111] and [100] oriented films. The optical absorption coefficient $(\alpha(v))$ was obtained by an ATI Unicam UV/Vis spectrometer (UV2200) to extract the Urbach energy $\left(E_{u}\right)$, and scanning electron microscope (SEM) images were taken using a LEO GEMINI 1530VP FEG-SEM system with an operating voltage of 3 $\mathrm{kV}$.

\section{Results and Discussion}

The XRD patterns of $\mathrm{Cu}_{2} \mathrm{O}$ films grown at different $i_{C}$ values are shown in Fig. 1 . The $\mathrm{Cu}_{2} \mathrm{O}$ (111) peak is detected for $i_{C} \geq 1.5 \mathrm{~A}$ (a lower $J_{i} / J_{C u}$ ), while the intense peak related to the $\mathrm{Cu}_{2} \mathrm{O}$ (200) plane is observed for $i_{C}<1.5 \mathrm{~A}$ (a higher $J_{i} / J_{C u}$ ). On the basis of the evolutionary selection theory based on the growth rate anisotropy of the different crystalline planes [12,19], it is proposed that for $i_{C}<1.5 \mathrm{~A}$ (i.e. a higher $J_{i} / J_{C u}$ ), the grains with the (200) plane parallel to the substrate surface would grow faster and at the expense of those (with the 
(111) plane parallel to the surface) grown by a slower vertical growth rate, and this results in the [100] preferred grain orientation despite its relatively higher surface energy. Given that an increase in $J_{i} / J_{C u}$ leads to a higher adatom mobility, this result is consistent with the work of Wang showing that the [100] preferred orientation with high surface energy can be obtained by an increase in adatom mobility [14]. In addition, contrary to a gradual transition of preferred grain orientation in polycrystalline TaN films from [111] to [111] $+[001]$ and to complete [001] with an increase in $J_{i} / J_{T a}$ [20], $\mathrm{Cu}_{2} \mathrm{O}$ films grown by the HiTUS system show an abrupt transition between [111] and [100] as seen in Fig. 1.

In order to investigate the grain orientation effect on the in-plane carrier mobility in $\mathrm{Cu}_{2} \mathrm{O}$ films, the samples grown at $i_{C}=1.38 \mathrm{~A}$ and $i_{C}=1.52 \mathrm{~A}$ were selected as the [100] and [111]oriented films, respectively, and $\mu_{\text {Hall }}$ of the as-deposited and annealed films was measured as seen in Fig. 2 . This shows that both as-deposited films exhibit a similar $\mu_{\text {Hall }}$, but a distinct difference in the extent of mobility enhancement appears as a result of annealing with the [100]-oriented film showing a more significant enhancement of $\mu_{\text {Hall }}$. The [100]-oriented film annealed at $700{ }^{\circ} \mathrm{C}$ shows a $\mu_{\text {Hall }}$ of $28 \mathrm{~cm}^{2} / \mathrm{V} \cdot \mathrm{s}$ which is one of the highest values obtained by sputtered copper oxide films [21-23].

Based on the assumption that $\mathrm{Cu}_{2} \mathrm{O}$ has a perfect single crystal structure, the effective mass for the light hole band situated at the top of the valence band was found to be isotropic by density functional theory calculations [24]. This means that a defect-free $\mathrm{Cu}_{2} \mathrm{O}$ grain is expected to have the same carrier mobility regardless of its crystallographic orientation. However, a nanocrystalline $\mathrm{Cu}_{2} \mathrm{O}$ film has grain boundaries with a high degree of structural 
disorder causing many defects, which impedes lateral carrier transport. It is well-known that Urbach energy $\left(E_{u}\right)$ is a measure of structural disorder $[25,26]$, and in polycrystalline films, it is assumed that $E_{u}$ is caused by several factors such as strain and bulk and grain boundary carrier trapping [27]. A theoretical analysis indicated that the disorder distribution is gradual with a maximum close to the grain boundary and decreases toward the center of the grain [28]. Furthermore, an inverse correlation between $E_{u}$ and grain size is widely observed [21, 28]. Both theoretical and experimental results indicate that the grain boundary is the main source of disorder in polycrystalline films. For this reason, the level of structural disorder in the films is compared by $E_{u}$ extracted using the following method in order to interpret the $\mu_{\text {Hall }}$ results.

The optical absorption tail follows the empirical exponential law represented by $\alpha(v)=$ $\alpha_{0} \exp \left(h v / E_{u}\right)$, where $\alpha, \alpha_{0}, h$ and $v$ denote the optical absorption coefficient, a constant, the Planck constant and the photon frequency, respectively [29,30]. This equation can be expressed as $\ln (\alpha)=\left(1 / E_{u}\right)(h v)-\ln \left(\alpha_{0}\right)$, and therefore $E_{u}$ can be extracted from the reciprocal of the slope of the linear region in the $\ln (\alpha)$ versus $h v$ (i.e. photon energy) plot as seen in Fig. 3a. The extracted $E_{u}$ values of the [111] and [100]-oriented $\mathrm{Cu}_{2} \mathrm{O}$ films are shown in Fig. 3b as a function of annealing temperature, which provides an insight into the $\mu_{\text {Hall }}$ results. The similar $\mu_{\text {Hall }}$ in the as-deposited films can be explained by the isotropic hole effective mass (i.e. the same mobility in defect-free grains in the direction of [100] and [111]) and a similar $E_{u}$ (i.e. a similar degree of disorder in the films). The more significant enhancement of $\mu_{\text {Hall }}$ in the [100]-oriented film after annealing is considered to be due to a more considerable 
reduction of disorder in the film than that in the [111]-oriented film based on the extracted $E_{u}$

In order to identify the main cause of the more significant reduction in disorder in the [100]-oriented film, the crystallographic characteristics and surface morphology of the $700{ }^{\circ} \mathrm{C}$-annealed films were investigated by XRD and SEM. The XRD patterns (Fig. 4) of the [111] and [100]-oriented films annealed at $700{ }^{\circ} \mathrm{C}$ were obtained from the same XRD system and measurement set-up as described in section 2 (Experimental Details). This clearly shows that the intensity $(I)$ of the diffraction peak of the [100]-oriented $\mathrm{Cu}_{2} \mathrm{O}$ film increases much more significantly after annealing $\left(I_{(200)}: 95\right.$ counts per second (cps) (as-deposited) $\rightarrow$ $4175 \mathrm{cps}\left(700{ }^{\circ} \mathrm{C}\right), I_{(111)}: 188 \mathrm{cps}($ as-deposited $\left.) \rightarrow 298 \mathrm{cps}\left(700{ }^{\circ} \mathrm{C}\right)\right)$. This indicates that the crystallinity of the [100]-oriented film improves more considerably than that of the [111]oriented film after annealing. In addition, it is observed that the (111) peak of the [111]oriented $\mathrm{Cu}_{2} \mathrm{O}$ film shifts from $36.74^{\circ}$ (as-deposited) to $36.46^{\circ}\left(700{ }^{\circ} \mathrm{C}\right.$ ) which is closer to the reference peak of $36.44^{\circ}$ [JCPDS 04-007-9767]. This can be explained by the release of the compressive stress in the film by annealing considering the fact that the compressive stress gives rise to a reduction in the lattice constant and this in turn results in a shift of its diffraction peak to a higher angle on the basis of Bragg's law. The SEM images (Fig. 5) show an interesting outcome that grains in the [100]-oriented film seem to be completely coalesced by annealing of $700{ }^{\circ} \mathrm{C}$ contrary to those in the [111]-oriented film. This experimental result suggests that the [100] texture with a higher surface energy is favorable for grain growth (i.e. grain coalescence) by annealing. This is considered to be the main reason for the more 
significant improvement in crystallinity and greater reduction in disorder in the [100]oriented film compared to the [111]-oriented film after annealing, which in turn results in a much higher carrier mobility in the [100]-oriented film.

\section{Conclusions}

It was demonstrated that the grain orientation in $\mathrm{Cu}_{2} \mathrm{O}$ films can be controlled in the direction of either [111] or [100] by a change in adatom mobility through adjusting the ion current (i.e. the ion-to-Cu flux ratio $\left(J_{i} / J_{C u}\right)$ incident at the growing film) using the HiTUS technique. To be specific, a low $J_{i} / J_{C u}$ leads to the growth of nanocrystalline $\mathrm{Cu}_{2} \mathrm{O}$ films with the [111] surface orientation which has the lowest surface energy, while an increase in $J_{i} / J_{C u}$ yields $\mathrm{Cu}_{2} \mathrm{O}$ films with the [100] orientation of the highest surface energy. In addition, a systematic study on the grain orientation effect on the in-plane carrier mobility in $\mathrm{Cu}_{2} \mathrm{O}$ films was performed. This shows that as-deposited films exhibit a similar carrier mobility for both grain orientations due to an isotropic hole effective mass and a similar degree of disorder in the films. By contrast, after annealing, the [100]-oriented film shows a more significant improvement in the carrier mobility due to a greater reduction in the degree of disorder in the film. Lastly, the [100] texture with a higher surface energy was found to be favorable for grain coalescence by annealing, which provides an insight into the higher crystallinity and lower degree of disorder in the [100]-oriented film after annealing. These experimental results suggest that the [100] preferred texture is favorable for device applications such as ptype metal oxide TFTs requiring a high in-plan carrier mobility. 


\section{Acknowledgements}

This work was supported by the Engineering and Physical Sciences Research Council under Grant No. EP/M013650/1. Additional data related to this publication is available at the DSpace@Cambridge data repository (http://www.repository.cam.ac.uk). 


\section{References}

[1] H. Raebiger, S. Lany, A. Zunger, Origins of the p-type nature and cation deficiency in $\mathrm{Cu}_{2} \mathrm{O}$ and related materials, Phys. Rev. B $76 \quad$ (2007) 045209. https://doi.org/10.1103/PhysRevB.76.045209.

[2] H. Kawazoe, H. Yanagi, K. Ueda, H. Hosono, Transparent p-Type conducting oxides: Design and fabrication of $p-n$ heterojunctions, MRS Bull. 25 (2000) 28-36. https://doi.org/10.1557/mrs2000.148.

[3] H. Yanagi, H. Kawazoe, A. Kudo, M. Yasukawa, H. Hosono, Chemical design and thin film preparation of $p$-Type conductive transparent oxides, J. Electroceram. 4 (2000) 407-414. https://doi.org/10.1023/A:1009959920435.

[4] S. Han, A.J. Flewitt, Analysis of the conduction mechanism and copper vacancy density in p-type $\mathrm{Cu}_{2} \mathrm{O}$ thin films, Sci. Rep. 7 (2017) 5766. https://doi.org/10.1038/s41598-01705893-x.

[5] S. Han, K.M. Niang, G. Rughoobur, A.J. Flewitt, Effects of post-deposition vacuum annealing on film characteristics of p-type $\mathrm{Cu}_{2} \mathrm{O}$ and its impact on thin film transistor $\begin{array}{llllll}\text { characteristics, } & \text { Appl. } & \text { Phys. } & \text { Lett. } & 109 & \text { (2016) }\end{array}$ https://doi.org/10.1063/1.4965848.

[6] T.D. Golden, M.G. Shumsky, Y. Zhou, R.A. VanderWerf, R.A. Van Leeuwen, J.A. Switzer, Electrochemical Deposition of Copper(I) Oxide Films, Chem. Mater. 8 (1996) 2499-2504. https://doi.org/10.1021/cm9602095. 
[7] L.C. Wang, N.R. de Tacconi, C.R. Chenthamarakshan, K. Rajeshwar, M. Tao, Electrodeposited copper oxide films: Effect of bath $\mathrm{pH}$ on grain orientation and orientation-dependent interfacial behavior, Thin Solid Films 515 (2007) 3090-3095. https://doi.org/10.1016/j.tsf.2006.08.041.

[8] S. Bijani, L. Martínez, M. Gabás, E.A. Dalchiele, J.R. Ramos-Barrado, Low-temperature electrodeposition of $\mathrm{Cu}_{2} \mathrm{O}$ thin films: modulation of micro-nanostructure by modifying the applied potential and electrolytic bath pH, J. Phys. Chem. C 113 (2009) 1948219487. https://doi.org/10.1021/jp905952a.

[9] W. Wu, K. Feng, B. Shan, N. Zhang, Orientation and grain shape control of $\mathrm{Cu}_{2} \mathrm{O}$ film and the related properties, Electrochimica Acta 176 (2015) 59-64. https://doi.org/10.1016/j.electacta.2015.06.010.

[10] C. Wang, J. Xu, S. Shi, Y. Zhang, Z. Liu, X. Zhang, S. Yina, L. Li, Structural, optical and photoelectrical properties of $\mathrm{Cu}_{2} \mathrm{O}$ films electrodeposited at different $\mathrm{pH}, \mathrm{RSC} \mathrm{Adv}$. 6 (2016) 4422-4428. https://doi.org/10.1039/C5RA23216C.

[11] R. Banerjee, R. Chandra, P. Ayyub, Influence of the sputtering gas on the preferred orientation of nanocrystalline titanium nitride thin films, Thin Solid Films 405 (2002) 64-72. https://doi.org/10.1016/S0040-6090(01)01705-9.

[12] S. Nicolay, S. Fay, C. Ballif, Growth model of MOCVD polycrystalline ZnO, Cryst. Growth Des. 9 (2009) 4957-4962. https://doi.org/10.1021/cg900732h.

[13] L. Fanni, A.B. Aebersold, M. Morales-Masis, D.T.L. Alexander, A. Hessler-Wyser, S. Nicolay, C. Hébert, C. Ballif, Increasing polycrystalline zinc oxide grain size by control 
of film preferential orientation, Cryst. Growth Des. 15 (2015) 5886-5891. https://doi.org/10.1021/acs.cgd.5b01299.

[14] Y. Wang, J. Ghanbaja, F. Soldera, S. Migot, P. Boulet, D. Horwat, F. Muecklich, J.-F. Pierson, Tuning the structure and preferred orientation in reactively sputtered copper oxide thin films, Appl. Surf. Sci. $335 \quad$ (2015) 85-91. https://doi.org/10.1016/j.apsusc.2015.02.028.

[15] Z. Zheng, B. Huang, Z. Wang, M. Guo, X. Qin, X. Zhang, P. Wang, Y. Dai, Crystal faces of $\mathrm{Cu}_{2} \mathrm{O}$ and their stabilities in photocatalytic reactions, J. Phys. Chem. C 113 (2009) 14448-14453. https://doi.org/10.1021/jp904198d.

[16] L. Hultman, J.-E. Sundgren, J.E. Greene, D.B. Bergstrom, I. Petrov, High-flux lowenergy $(20 \mathrm{eV}) \mathrm{N}_{2}{ }^{+}$ion irradiation during TiN deposition by reactive magnetron sputtering: Effects on microstructure and preferred orientation, J. Appl. Phys. 78 (1995) 5395-5403. https://doi.org/10.1063/1.359720.

[17] D. Gall, S. Kodambaka, M.A. Wall, I. Petrov, J.E. Greene, Pathways of atomistic processes on TiN(001) and (111) surfaces during film growth: an ab initio study, J. Appl. Phys. 93 (2003) 9086-9094. https://doi.org/10.1063/1.1567797.

[18] A.J. Flewitt, J.D. Dutson, P. Beecher, D. Paul, S.J. Wakeham, M.E. Vickers, C. Ducati, S.P. Speakman, W.I. Milne, M.J. Thwaites, Stability of thin film transistors incorporating a zinc oxide or indium zinc oxide channel deposited by a high rate sputtering process, Semicond. Sci. Technol. $24 \quad$ (2009) 085002. http://dx.doi.org/10.1088/0268-1242/24/8/085002. 
[19] A. van der Drift, Evolutionary selection, a principle governing growth orientation in vapour-deposited layers, Phillips Res. Rep. 22 (1967) 267-288.

[20] I. Petrov, P.B. Barna, L. Hultman, J.E. Greene, Microstructural evolution during film $\begin{array}{llllllll}\text { growth, J. } & \text { Vac. } & \text { Sci. Technol. } & \text { A } & 21 & \text { (2003) S117-S128. }\end{array}$ https://doi.org/10.1116/1.1601610.

[21] Y. Wang, P. Miska, D. Pilloud, D. Horwat, F. Mucklich, J. F. Pierson, Transmittance enhancement and optical band gap widening of $\mathrm{Cu}_{2} \mathrm{O}$ thin films after air annealing. J. Appl. Phys. 115 (2014) 073505. http://dx.doi.org/10.1063/1.4865957.

[22] E.-S. Cho, J. Sohn, S.-H. Song, H.-I. Kwon, Active layer thickness effects on the structural and electrical properties of p-type $\mathrm{Cu}_{2} \mathrm{O}$ thin-film transistors, J. Vac. Sci. Technol. B 30 (2012) 060605. https://doi.org/10.1116/1.4764110.

[23] K.C. Sanal, L.S. Vikas, M.K. Jayaraj, Room temperature deposited transparent pchannel $\mathrm{CuO}$ thin film transistors, Appl. Surf. Sci. 297 (2014) 153-157. https://doi.org/10.1016/j.apsusc.2014.01.109.

[24] X. Nie, S.-H. Wei, S.B. Zhang, First-principles study of transparent $p$-type conductive $\mathrm{SrCu}_{2} \mathrm{O}_{2}$ and related compounds, Phys. Rev. B 65 (2002) 075111. https://doi.org/10.1103/PhysRevB.65.075111.

[25] D. Nesheva, Z. Levi, Z. Aneva, V. Nikolova, H. Hofmeister, Experimental studies on the defect states at the interface between nanocrystalline CdSe and amorphous SiOx, J. Phys.: Condens. Matter. 12 (2000) 751-759. 
[26] S. Ahmad, K. Asokan, M. Zulfequar, Investigation of structural and optical properties of $100 \mathrm{MeV} \mathrm{F}^{7+}$ ion irradiated $\mathrm{Ga}_{10} \mathrm{Se}_{90-\mathrm{x}} \mathrm{Al}_{\mathrm{x}}$ thin films, Philos. Mag. 95 (2015) 13091320. https://doi.org/10.1080/14786435.2015.1023860S0953-8984(00)05981-6.

[27] D. Dragoman, M. Dragoman, Optical Characterization of Solids, first ed., Springer, Heidelberg, 2002

[28] A. Iribarren, R. Castro-Rodriguez, F. Caballero-Briones, J. L. Pena, Optical and structural evidence of the grain-boundary influence on the disorder of polycrystalline CdTe films, Appl. Phys. Lett. 74 (1999) 2957-2959. https://doi.org/10.1063/1.123978.

[29] Y. Natsume, H. Sakata, T. Hirayama, Low-temperature electrical conductivity and optical absorption edge of $\mathrm{ZnO}$ films prepared by chemical vapour deposition, Phys. Status Solidi A 148 (1995) 485-495. https://doi.org/10.1002/pssa.2211480217.

[30] S.J. Ikhmayies, R.N. Ahmad-Bitar, A study of the optical bandgap energy and Urbach tail of spray-deposited CdS:In thin films, J. Mater. Res. Technol. 2 (2013) 221-227. https://doi.org/10.1016/j.jmrt.2013.02.012.

\section{List of figure captions}

Fig. 1. X-ray diffraction patterns of $\mathrm{Cu}_{2} \mathrm{O}$ films deposited at various ion currents. A small peak from the sample holder is also present.

Fig. 2. Hall mobility of [100] and [111]-oriented $\mathrm{Cu}_{2} \mathrm{O}$ films as a function of annealing temperature. Inset shows a schematic van der Pauw geometry for the Hall-effect measurement. 
Fig. 3. (a) $\ln (\alpha)$ versus photon energy plots of [111] and [100]-oriented $\mathrm{Cu}_{2} \mathrm{O}$ films with different annealing temperatures and (b) their extracted Urbach energy as a function of annealing temperature.

Fig. 4. X-ray diffraction patterns of the [100] and [111]-oriented $\mathrm{Cu}_{2} \mathrm{O}$ films annealed at $700{ }^{\circ} \mathrm{C}$.

Fig. 5. Scanning electron microscope images of (a) [100] and (b) [111]-oriented $\mathrm{Cu}_{2} \mathrm{O}$ films annealed at $700{ }^{\circ} \mathrm{C}$. 


\section{Figures}

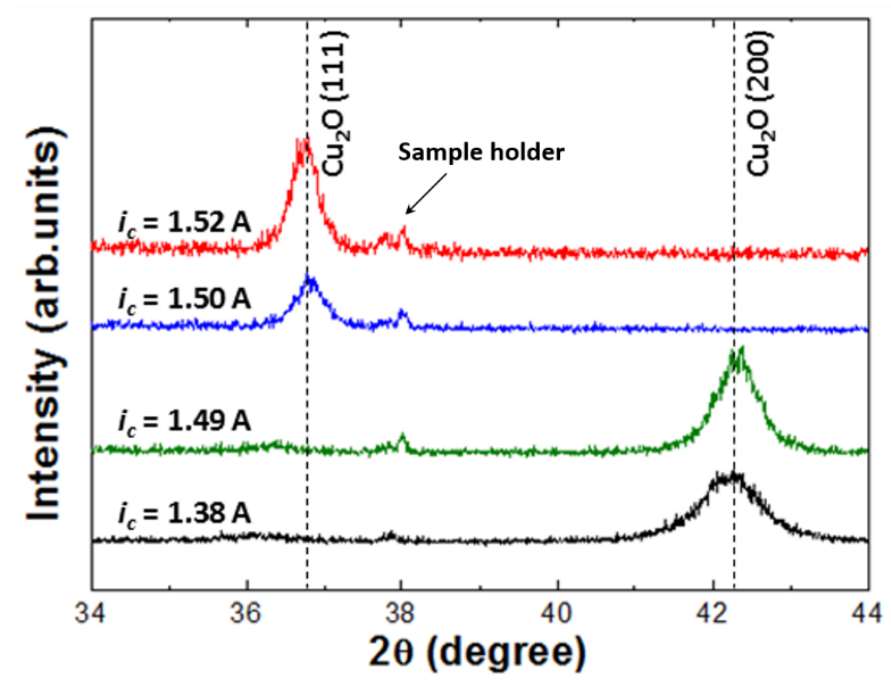

FIG. 1. X-ray diffraction patterns of $\mathrm{Cu}_{2} \mathrm{O}$ films deposited at various ion currents. A small peak from the sample holder is also present.

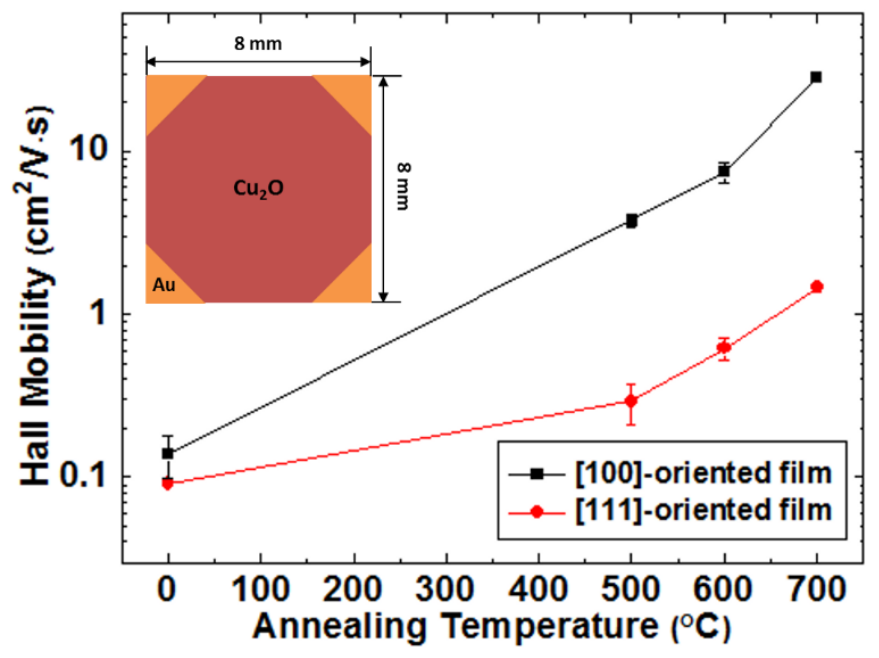

FIG. 2. Hall mobility of [100] and [111]-oriented $\mathrm{Cu}_{2} \mathrm{O}$ films as a function of annealing temperature. Inset shows a schematic van der Pauw geometry for the Hall-effect measurement. 

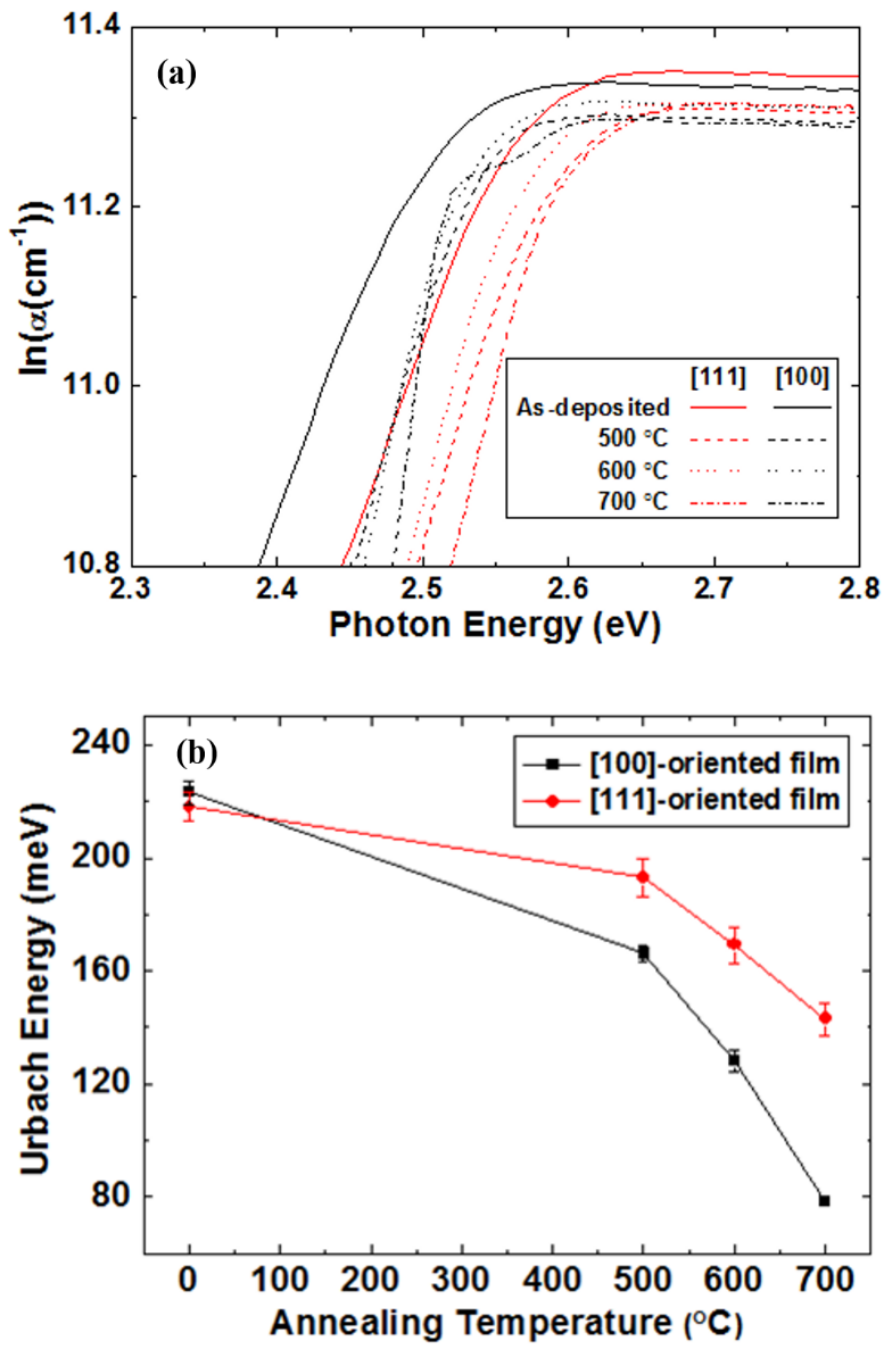

FIG. 3. (a) $\ln (\alpha)$ versus photon energy plots of [111] and [100]-oriented $\mathrm{Cu}_{2} \mathrm{O}$ films with different annealing temperatures and (b) their extracted Urbach energy as a function of annealing temperature. 


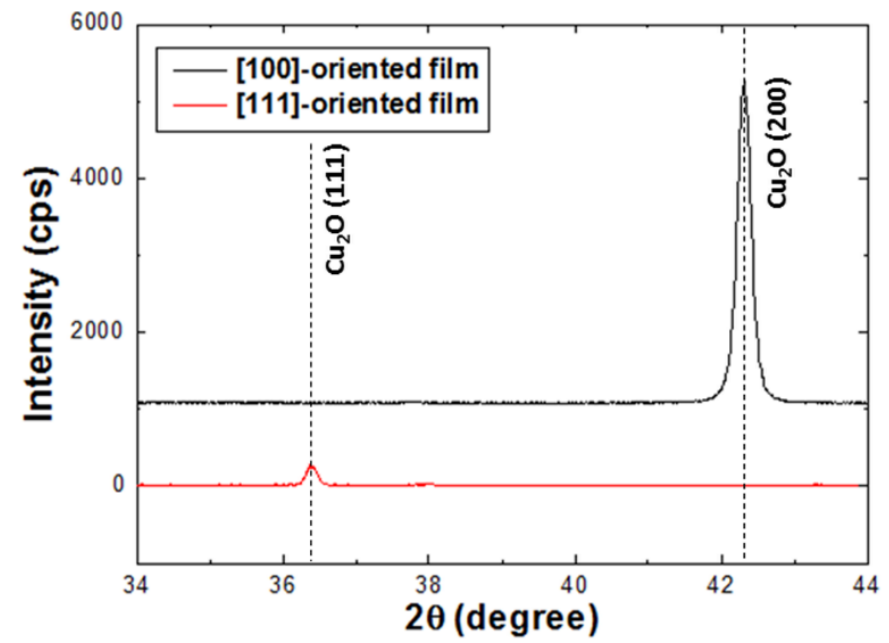

FIG. 4. X-ray diffraction patterns of the [100] and [111]-oriented $\mathrm{Cu}_{2} \mathrm{O}$ films annealed at $700{ }^{\circ} \mathrm{C}$. 

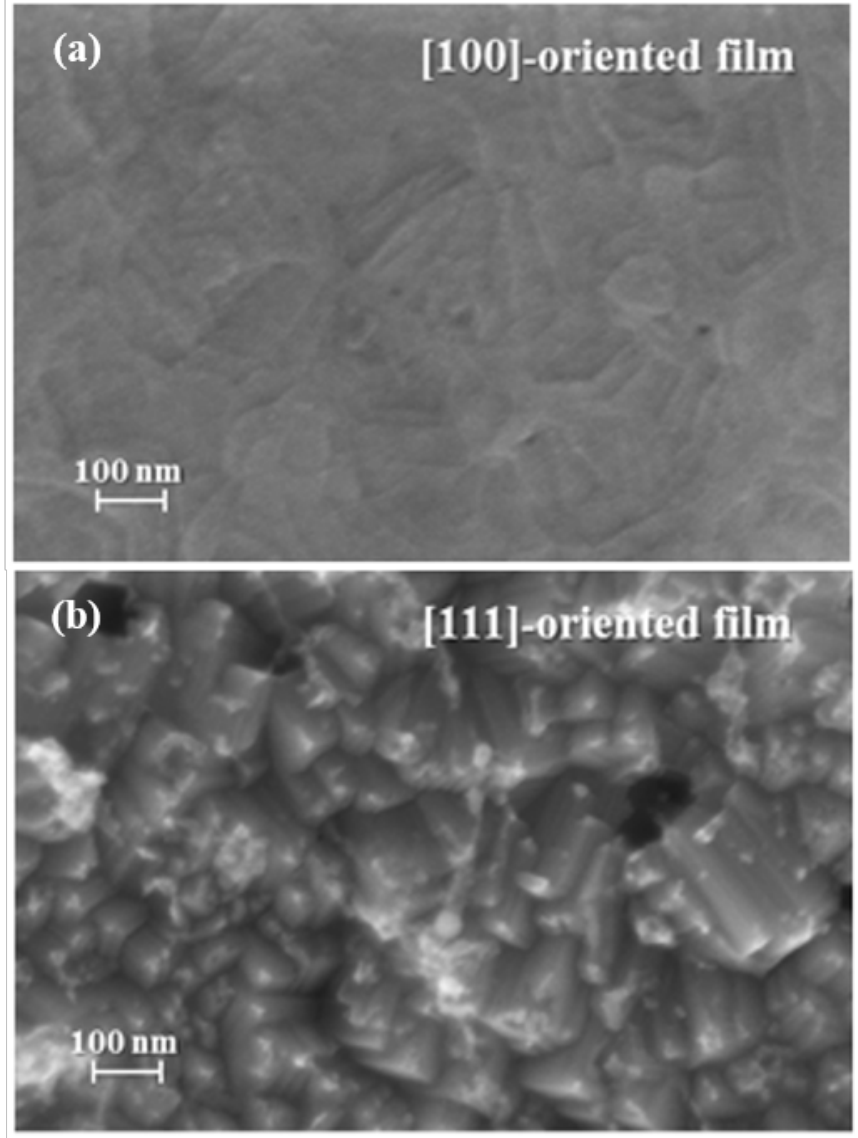

FIG. 3. Scanning electron microscope images of (a) [100] and (b) [111]-oriented $\mathrm{Cu}_{2} \mathrm{O}$ films annealed at $700{ }^{\circ} \mathrm{C}$. 